\title{
Preparation and Proton Conductivity of Polymer Electrolytes Based on Alginic Acid and 1,2,4-Triazole
}

\author{
By Şeyda T. GÜNDAY and Ayhan BOZKURT*
}

In this work, novel proton conducting anhydrous polymer electrolytes based on alginic acid (AL) and 1,2,4-Triazole (Tri) were investigated. The biomaterials were prepared by the combination of alginic acid with a heterocyclic protogenic solvent, 1,2,4-triazole at several molar ratios, $\mathrm{x}$ to form $\mathrm{ALTri}_{\mathrm{x}}$. The materials can be cast into transparent, homogeneous thin films $(50-100 \mu \mathrm{m})$. FT-IR spectroscopy suggested the proton exchange reactions between -COOH group of AL and Tri. Thermal properties of the materials were studied via thermogravimetic analysis (TG) and differential scanning calorimetry (DSC). The $\mathrm{X}$-ray diffraction (XRD) study reveals the amorphous nature of the ALTri ${ }_{\mathrm{x}}$ electrolytes. Proton conductivity increases with the Tri content and ALTri ${ }_{1.5}$ exhibited approximate maximum conductivity of $\sim 0.1 \mathrm{mS} / \mathrm{cm}$ at $100^{\circ} \mathrm{C}$.

KEY WORDS: Alginic Acid / Triazole / Biomaterials / Polymer Electrolyte / Proton Conductivity /

Alginic acid is a naturally occurring biopolymer obtained from the various species of brown seaweed. It is a linear copolymer consisting of (1-4)-linked $\beta$-D-mannuronate (M) and $\alpha$-L-guluronic acid (G) which are covalently linked together in different sequences or blocks ${ }^{1}$ (Figure 1). The properties of alginic acid have been explored in many different fields due to their ion-exchange ability, metal ion absorption capacity, biocompatible and non-toxic properties. ${ }^{2,3}$ Therefore, alginic acid has already established its application in the food, pharmacological and medical industries and environment. ${ }^{2,4-6}$

This major polysaccharide structurally contains carboxylic acid groups in each repeating unit and possesses various abilities for functional materials. Considering the abundance as natural source, it is meaningful to develop new possibilities for application. Alternatively, the utilization of alginic acid as a matrix in water-free proton conducting host-guest systems can be interesting due to low product cost and environmental safety.

The interest in anhydrous proton conducting polymers has been revived in the last few decades as their potential application in fuel cells. ${ }^{7,8}$ A general approach for the synthesis of these materials was the doping of proton solvents into a polymeric matrix so that proton transport occurs almost entirely through structure diffusion. ${ }^{8,9}$ The procedure involved either the blending of neutral/basic polymers with phosphoric $\operatorname{acid}^{8-12}$ or doping of acidic polymers with heterocyclic structures. $^{13-15}$ In the former, plasticized materials with maximum anhydrous proton conductivity of $10^{-2}-10^{-4} \mathrm{~S} /$ $\mathrm{cm}$ were obtained. In the latter approach, materials incorporating heterocyclic structures such as imidazole or benzimidazole enhanced defect type proton conductivity to $10^{-3}-10^{-2}$ $\mathrm{S} / \mathrm{cm}$.

$1 \mathrm{H}-1,2,4-$ Triazole $\left(\mathrm{mp}: 120^{\circ} \mathrm{C}\right.$, bp: $260^{\circ} \mathrm{C}$ ) is a crystalline solid at room temperature and unlike imidazole it contains three nitrogen atoms in the ring. The use of 1,2,4-triazole (Tri) as proton transport facilitator in acidic biopolymers can be a new avenue for the development of non-aqueous polymer electrolytes. The molecular structure of Tri is similar to imidazole and may also allow structure diffusion, i.e., proton transport between protonated and unprotonated heterocycles through hopping and reorientation. ${ }^{16-18}$

In the present work, we produced model proton conducting polymer electrolytes through doping of 1,2,4-triazole into an acidic biopolymer, alginic acid (AL) (Figure 1). Transparent, homogeneous thin films of $\mathrm{ALTri}_{\mathrm{x}}$ were obtained where $\mathrm{x}$ is the molar ratio of Tri to carboxylic acid unit of AL. The materials were characterized by FT-IR, TG, DSC and XRD methods. The proton conductivity of the polymer electrolytes was measured by impedance spectroscopy.

\section{EXPERIMENTAL}

\section{Materials and Preparation}

Commercial alginic acid (molecular weight $240 \mathrm{kDa}$ ) which contains approximately $61 \%$ mannuronic acid and $39 \%$ gluronic acid was obtained from Sigma. 1,2,4-triazole (SigmaAldrich) was used as received. The recipe of preparation of $\mathrm{ALTri}_{1}$ complex electrolytes is as follows: $1 \mathrm{~g}$ of $\mathrm{AL}$ was dissolved in $10 \mathrm{~mL}$ of water, then 0.392 (6 mmol) Tri was admixed and the solution was stirred overnight. After obtaining a homogeneous mixture, the gels were cast on Teflon ${ }^{\circledR}$ plates and dried at $50{ }^{\circ} \mathrm{C}$ under atmospheric pressure, then further dried under vacuum at the same temperature during $24 \mathrm{~h}$. Transparent, homogeneous films were obtained with a thickness ranging from 50 to $100 \mu \mathrm{m}$ (Figure 2). Similar procedures were followed for the preparation of other compositions. $\operatorname{ALTri}_{\mathrm{x}}(\mathrm{x}=1.5)$ is the maximum doping level above which the materials lost their transparency and become heterogeneous. 


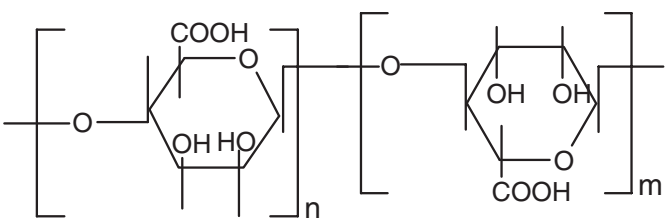

AL<smiles>c1nc[nH]n1</smiles>

Tri
Figure 1. The molecular structures of $A L$ and Tri.

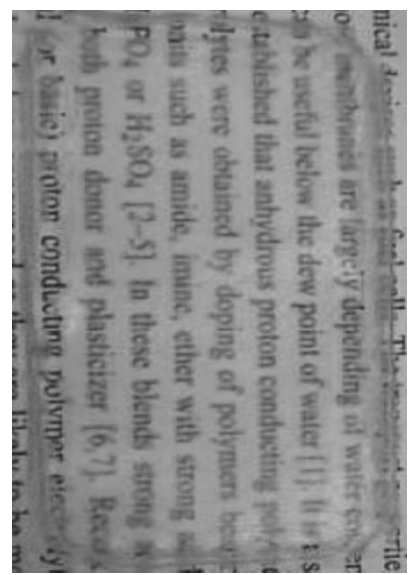

Figure 2. Appearance of $A \mid T r i_{1}$, : the free standing film $(3.5 \mathrm{~cm} \times 7 \mathrm{~cm})$ is transparent and homogeneous and can be bended to a certain level.

\section{Characterizations of Complex Electrolytes}

FT-IR spectra were recorded on a Mattson Genesis II spectrophotometer by depositing thin sample films onto silicon wafers.

Thermogravimetric analyses were carried out using TGA Mettler TG50 instrument. The temperature range of $25-600^{\circ} \mathrm{C}$ was scanned at a heating rate of $10^{\circ} \mathrm{C} / \mathrm{min}$ under a nitrogen atmosphere.

Differential scanning calorimetry (DSC) was used to determine the thermal transitions of the complex electrolytes. The DSC analysis was carried out using Mettler DSC TA 3000 scanning calorimeter. The samples $(10-15 \mathrm{mg}$ ) were filled into aluminum pans and then heated to the desired temperature with a rate of $10^{\circ} \mathrm{C} / \mathrm{min}$ under a nitrogen atmosphere.

$\mathrm{X}$-Ray powder diffraction (XRD) patterns were obtained using Rigaku diffractometer $(\mathrm{Cu} \mathrm{K} \alpha)$ with $\mathrm{D} / \max$ RINT 2200. Powder samples were adhered onto a glass slide. The glass slide was then placed in the sample holder of the diffractometer and the angle of diffraction was varied from $0^{\circ}$ to $70^{\circ}$.

The impedance data were recorded using a SI 1260Schlumberger impedance analyzer. The measurements were carried out in the Max-Planck Institute for Polymer Research, Mainz-Germany. The thin films of the samples were placed between gold electrodes and their conductivities were measured in a frequency range from $0.1 \mathrm{~Hz}$ to $1 \mathrm{MHz}$ and the temperature range from $0{ }^{\circ} \mathrm{C}$ to $100{ }^{\circ} \mathrm{C}$ with $10^{\circ} \mathrm{C}$ intervals.

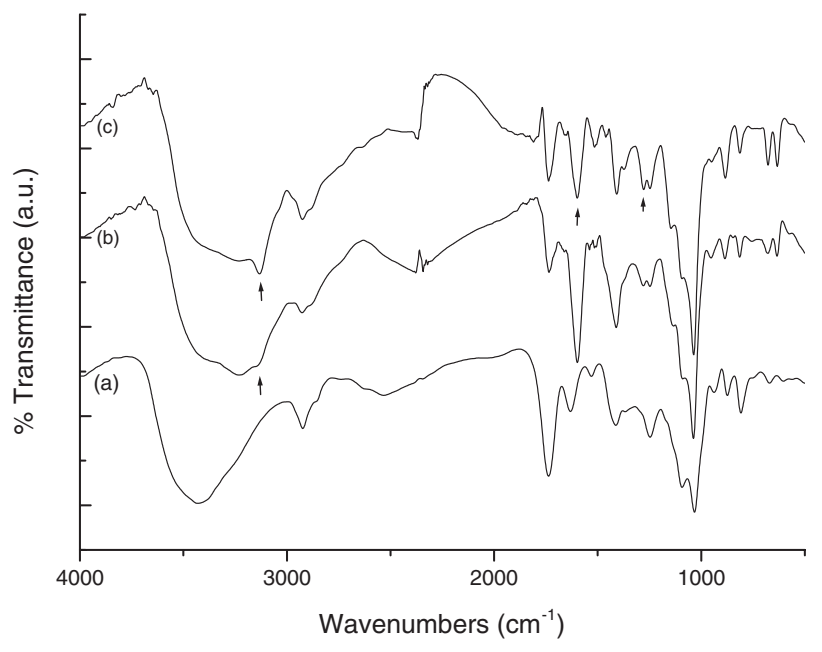

Figure 3. FT-IR spectra of the biopolymer and composite electrolytes, AL (a) $\mathrm{ALTri}_{0.5}$ (b) and ALTri ${ }_{1}$ (c).

\section{RESULTS AND DISCUSSION}

Single phase alginic acid-1,2,4-triazole polymer electrolytes were produced through doping of the biopolymer, AL with Tri at several stoichiometric ratios $\mathrm{x}$ to form ALTrix . One of the observed features of alginic acid is that it swells in water and forms turbid solutions. Upon addition of Tri, the color of the viscous solution becomes translucent irrespective to $\mathrm{x}$ and the $\mathrm{pH}$ of the solutions were in the range of 3.5-4. After drying the gels they form transparent films which do not break up on certain bending, as long as $\mathrm{x} \leq 1.5$.

Figure 3 presents the FT-IR spectra of the commercial alginic acid and $\mathrm{ALTri}_{\mathrm{x}}$ electrolytes. The prominent bands at $1731 \mathrm{~cm}^{-1}$ and $1628 \mathrm{~cm}^{-1}$ are assigned to $\mathrm{C}=\mathrm{O}$ stretching of carboxylic acid unit of AL (Figure 3a). The saccharide structure gives rise to $\mathrm{C}-\mathrm{O}-\mathrm{C}$ and $\mathrm{C}-\mathrm{OH}$ stretching in the region of 1200 1290 and $1000-1100 \mathrm{~cm}^{-1} .{ }^{19}$ When $\mathrm{Al}$ is complexed with Tri, the intensity of $\mathrm{C}=\mathrm{O}$ stretching at $1731 \mathrm{~cm}^{-1}$ decreased and peak at $1628 \mathrm{~cm}^{-1}$ disappeared. Moreover, new peak appeared at $1600 \mathrm{~cm}^{-1}$ and the intensity of the peak at $1410 \mathrm{~cm}^{-1}$ is increased. These respective bands are assigned to asymmetric and symmetric stretching of $-\mathrm{CO}_{2}{ }^{-}$units (Figure $3 \mathrm{~b}$ ). ${ }^{20}$ The intensity of N-H stretching peak at $3135 \mathrm{~cm}^{-1}$ also increases due to protonation of free nitrogen in the heterocyclic ring.

The thermal stability of the biopolymer and the polymer electrolytes was studied using TG analysis. The materials were dried under vacuum at $50{ }^{\circ} \mathrm{C}$ prior to measurements. Figure 4 shows the TG thermograms of AL, ALTri ${ }_{0.5}, \mathrm{ALTri}_{1}$ and $\mathrm{ALTri}_{1,5}$ from room temperature to $600^{\circ} \mathrm{C}$ at a heating rate of $10^{\circ} \mathrm{C} / \mathrm{min}$. Alginic acid shows initially dehydration process followed a one step decomposition above $185^{\circ} \mathrm{C}$. AlTri $\mathrm{Al}_{0.5}$ shows no weight change up to $155^{\circ} \mathrm{C}$ then it decomposes. Similarly, the onset of decomposition of both $\mathrm{AlTri}_{1}$ and $\mathrm{AlTri}_{1.5}$ is approximately $150^{\circ} \mathrm{C}$. A slight weight change below these temperatures can be attributed to loss of absorbed humidity. 


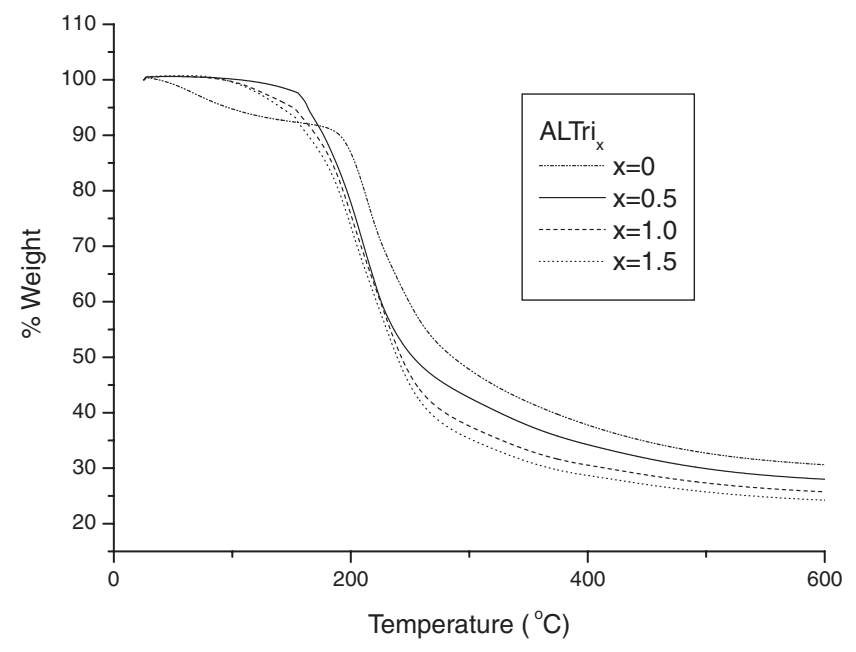

Figure 4. TG curves of Alginic acid and ALTri $x_{x}$ electrolytes.

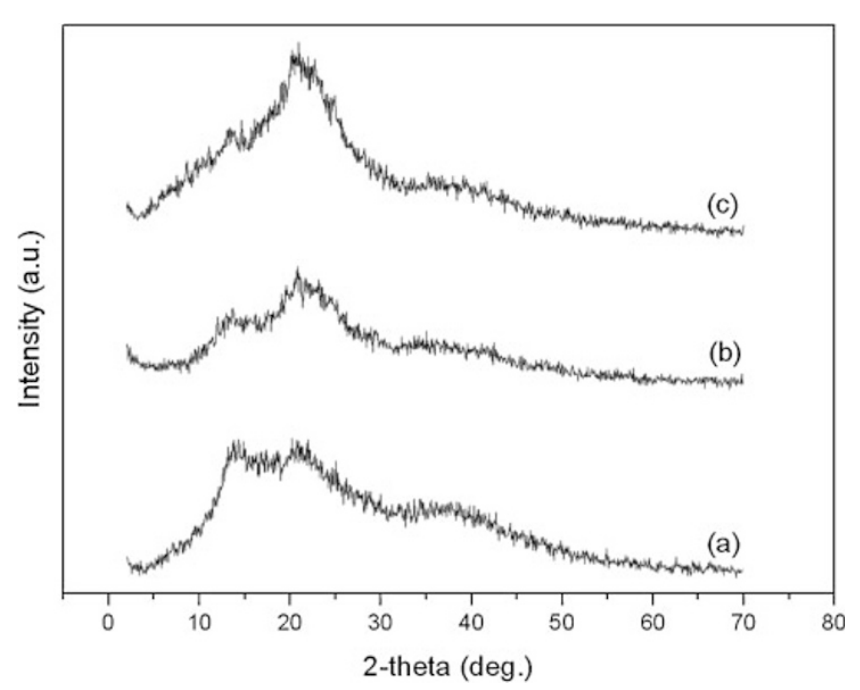

Figure 5. X-Ray diffraction patterns, Alginic acid (a) AlTri $\mathrm{A}_{0.5}$ (b) and AlTri ${ }_{1.5}$ (c).

Differential scanning calorimetry (DSC) was employed to determine thermal transitions in the polymer electrolytes. The measurements were carried out from $-100{ }^{\circ} \mathrm{C}$ to decomposition temperature of the complex electrolytes under nitrogen atmosphere and at a heating rate of $10^{\circ} \mathrm{C} / \mathrm{min}$. DSC results demonstrated no glass transitions up to onset of the degradation. The reason of such a behavior can be attributed to restriction of segmental relaxation of the host polymer through complexation. $^{21}$

Figure 5 shows the X-ray diffraction patterns of alginic acid and complex electrolytes. AL exhibits broad peaks around $2 \theta=14^{\circ}$ and $21^{\circ}$ which can be attributed to the amorphous structure. For ALTri ${ }_{1.5}$, the peak at $14^{\circ}$ almost disappeared and at $21^{\circ}$ become more intense as the complex formed between $\mathrm{AL}$ and Tri. These results showed that the difference in the intensities of the peaks for each composition reflects the sequential structure of complex electrolytes and $\mathrm{AlTri}_{1.5}$ has a

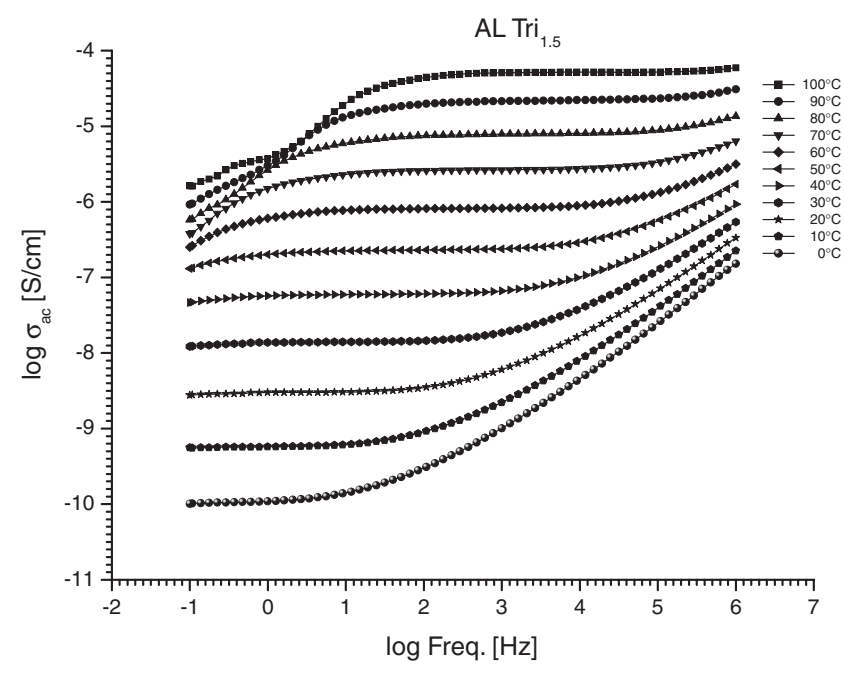

Figure 6. $\mathrm{AC}$ conductivity vs. $\log \mathrm{F}(\mathrm{Hz})$ of $A L T r i_{1.5}$ at various temperatures.

greater ordered morphology.

The AC conductivity data of $\mathrm{ALTri}_{\mathrm{x}}$ electrolytes were measured using an impedance spectroscopy within the frequency range $0.1 \mathrm{~Hz}$ to $1 \mathrm{Mhz}$. The samples were placed between gold electrodes and the complex conductivities were obtained at $10^{\circ} \mathrm{C}$ interval under nitrogen atmosphere. Figure 6 shows the AC conductivity $\left(\sigma_{\mathrm{ac}}\right)$ of $\mathrm{ALTri}_{1.5}$ versus frequency in a logarithmic scale. The curve comprises several regions depending on the temperature and frequency which are similar to other ion conducting polymers. ${ }^{15}$ Frequency independent conductivity regions which are formed at lower temperatures $\left(T=0-30^{\circ} \mathrm{C}\right)$ shifts to higher frequencies at higher temperatures. Moreover, normal dispersions in polymers can be observed at lower temperatures and higher frequencies, i.e., the conductivity increases sharply at $T=20^{\circ} \mathrm{C}$ and the frequency higher than $100 \mathrm{~Hz}$. When $T>50^{\circ} \mathrm{C}$, the irregularities at the low frequency side corresponds to electrode polarization. The DC conductivity $\left(\sigma_{\mathrm{dc}}\right)$ of the polymer electrolytes can be derived from the conductivity plateaus through linear fitting and extrapolating to the real axis.

The proton conductivities of the complex electrolytes were evaluated through heating and cooling cycles from $0{ }^{\circ} \mathrm{C}$ to $100^{\circ} \mathrm{C}$ at $10^{\circ} \mathrm{C}$ intervals. Arrhenius plots of the complex electrolytes with different concentrations of triazole are presented in Figure 7. The conductivities which are measured through heating or cooling are almost identical at the respective temperatures. This result shows the reproducibility of the proton conductivity when the samples have experienced temperatures up to $100{ }^{\circ} \mathrm{C}$. The conductivity $v s$. reciprocal temperature shows straight lines which indicate the absence of cooperative segmental relaxations as proved by DSC. The data suggested that the conduction mechanism can be described by the simple Arrhenius equation (Eq. 1).

$$
\sigma=\sigma_{\mathrm{o}} \exp \left(-\frac{\mathrm{E}_{\mathrm{a}}}{\mathrm{kT}}\right)
$$

where $\sigma_{\mathrm{o}}$ is the pre-exponential factor, $\mathrm{k}$ is the Boltzmann 


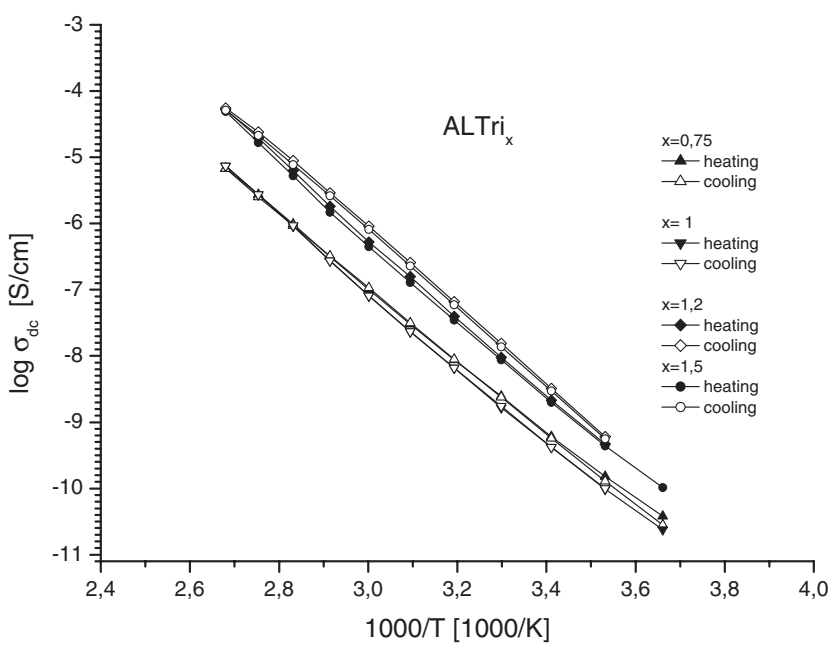

Figure 7. Proton conductivity versus reciprocal temperature of the complex electrolytes, ALTrix.

Table I. Pre-exponential factor, $\log \sigma_{\circ}$ and the activation energy, $E_{a}$ of ALTri electrolytes

\begin{tabular}{lcc}
\hline ALTri $_{\mathbf{x}}$ & $\log \sigma_{\mathbf{o}}$ & $\mathbf{E}_{\mathbf{a}}(\mathbf{e V})$ \\
\hline ALTri $_{0.75}$ & 9.3 & 1.1 \\
\hline ALTri $_{1}$ & 9.9 & 1.1 \\
\hline ALTri $_{1.5}$ & 11.3 & 1.2 \\
\hline
\end{tabular}

constant. $\mathrm{E}_{\mathrm{a}}$ is the activation energy which can be estimated form the slope of the conductivity isotherms, Figure 7.

The $\mathrm{E}_{\mathrm{a}}$ and $\log \sigma_{\mathrm{o}}$ values are compiled in Table I. Namely, proton transfer occur between triazole units with an activation energy that is comparable with other non-aqueous systems such as PVPA-imidazole composite electrolytes at the same doping ratios, i.e., $\mathrm{x}=1 .^{22}$ It was reported that high activation energy is due to long distance between hopping sites of heterocyclic units at lower doping ratios. ${ }^{13}$

It was previously reported that heterocyclic molecules such as imidazole contain two nitrogen atoms and allow proton transfer from imidazolium ion to imidazole through structural reorientation. ${ }^{16}$ Triazole has a molecular structure similar to imidazole but it bears three nitrogen atoms in the ring. Intramolecular proton transfer may occur by a process so called 'tautomerism' (Figure 8a). ${ }^{23}$ Intermolecular proton transfer may occur via proton exchange reactions between azole groups similar to imidazole (Figure $8 \mathrm{~b}$ ). ${ }^{16,18}$

In this system, proton transfer between triazolium ion and triazole is the determining factor for the proton diffusion, as already suggested for similar systems. ${ }^{16,24}$ Long range proton diffusion is expected to occur throughout the hydrogen-bonded network formed by heterocyclic rings, i.e., triazoles.

The proton conductivity of $\mathrm{ALTri}_{0.75}$ and $\mathrm{ALTri}_{1}$ are very close to each other within the temperature range of measurement. However, the conductivity increases at least one order of magnitude for $\mathrm{ALTri}_{1.2}$ and $\mathrm{ALTri}_{1.5}$. The reason can be explained by the number of Tri per polymer repeat unit where up to $\mathrm{x}=1$ all Tri is bound to ionic groups, while at $\mathrm{x}>1$ the (a)<smiles>c1nc[nH]n1</smiles>

(i)

(ii)

(b)

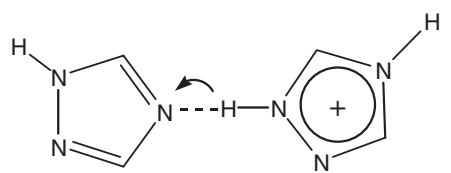

Figure 8. a) Intra-molecular proton transfer via tautomerism, $1 \mathrm{H}-1,2,4-$ triazole (i) $2 \mathrm{H}-1,2,4$-triazole (ii) b) Inter-molecular proton transfer.

existence of free Tri can contribute to conductivity through structure diffusion. Maximum proton conductivity of the complex electrolytes was measured to be approximately 0.1 $\mathrm{mS} / \mathrm{cm}$ at $100^{\circ} \mathrm{C}$.

\section{CONCLUSION}

In this work, synthesis and proton conducting properties of the biopolymer-heterocycle electrolytes were investigated. Alginic acid, AL was employed as a host matrix and triazole was used as the dopant. Transparent, homogeneous and thin films were obtained for $\operatorname{ALTri}_{\mathrm{x}}(\mathrm{x}=0.5-1.5)$ systems. FT-IR studies proved the coexistence of both protonated and unprotonated triazole units. The ALTri $\mathrm{x}_{\mathrm{x}}$ materials are thermally stable up to approximately $150{ }^{\circ} \mathrm{C}$. The X-ray diffraction (XRD) study showed that $\mathrm{AlTri}_{1.5}$ has a greater ordered morphology. DSC results and conductivity isotherms proved the restriction of the segmental relaxations of the polymer through complexation. An approximate proton conductivity of $\sim 0.1 \mathrm{mS} / \mathrm{cm}$ was obtained for ALTri ${ }_{1.5}$. The proton conductive $\mathrm{ALTri}_{\mathrm{x}}$ complex electrolytes have excellent film forming properties and can be considered for the application to electrochemical devices such as electrochromic devices and sensors.

Acknowledgment. This work was supported by TUBITAK$104 \mathrm{M} 220$.

Received: October 2, 2007

Accepted: October 22, 2007

Published: December 4, 2007

\section{REFERENCES}

1. X. Liu, L. Qian, T. Shu, and Z. Tong, Polymer, 44, 407 (2003).

2. H. Kitamura, E. Matsuura, A. Nagata, N. Sakairi, S. Tokura, and N. Nishi, Int. J. Biol. Macromol., 20, 75 (1997).

3. H. Ertesvåg and S. Valla, Polym. Degrad. Stab., 59, 85 (1998).

4. A. Ikeda, A. Takemura, and H. Ono, Carbohydr. Polym., 42, 421 (2000).

5. G. O. Aspinall, "The Polysaccharides", Academic Press, New York, 1983, Vol. 2.

6. K. Iwata, T. Sawadaishi, S. Nishimura, S. Tokura, and N. Nishi, Int. J. 
Biol. Macromol., 18, 149 (1996).

7. B. Smitha, S. Sridhar, and A. A. Khan, J. Membr. Sci., 259, 10 (2005).

8. M. F. H. Schuster and W. H. Meyer, Annu. Rev. Mater. Res., 33, 233 (2003).

9. K. D. Kreuer, J. Membr. Sci., 185, 29 (2001).

10. G. Alberti and M. Casciola, Solid State Ionics, 145, 3 (2001).

11. A. Bozkurt and W. H. Meyer, Solid State Ionics, 138, 259 (2001).

12. A. Bozkurt and W. H. Meyer, J. Polym Sci., Part B: Polym. Phys., 39, 1987 (2001).

13. M. Yamada and I. Honma, Polymer, 45, 8349 (2004).

14. A. Bozkurt, W. H. Meyer, and G. Wegner, J. Power Sources, 123, 126 (2003).

15. H. Erdemi, A. Bozkurt, and W. H. Meyer, Synth. Met., 143, 133 (2004).

16. W. Münch, K. D. Kreuer, W. Silvestri, J. Maier, and G. Seifert,
Solid State Ionics, 145, 437 (2001).

17. Z. Zhou, S. Li, Y. Zhang, M. Liu, and W. Li, J. Am. Chem. Soc., 127, 10824 (2005).

18. S. T. Günday, A. Bozkurt, W. H. Meyer, and G. Wegner, J. Polym Sci., Part B: Polym. Phys., 44, 3315 (2006).

19. C. Sartori, D. S. Finch, B. Ralph, and K. Gilding, Polymer, 38, 43 (1997).

20. R. Y. M. Huang, R. Pal, and G. Y. Moon, J. Membr. Sci., 160, 101 (1999).

21. A. Bozkurt, W. H. Meyer, J. Guttmann, and G. Wegner, Solid State Ionics, 164, 169 (2003).

22. M. Yamada and I. Honma, Polymer, 46, 2986 (2005).

23. G. Rauhut, Phys. Chem. Chem. Phys., 5, 791 (2003).

24. R. Subbaraman, H. Ghassemi, and T. Zawodzinski, J. Am. Chem. Soc., 129, 2238 (2007). 